\title{
Research on geometric error measurement system of machining center BV75 based on laser interferometer
}

\author{
Lijuan Shi, Jinying Chen, Zhaokun Li, Huamei Bian
}

Beijing Industry Vocational \& Technical college, Beijing 100042, China

\begin{abstract}
This paper measures the twenty one geometric errors of numerical control machining center with parameter identification through laser interferometer, the main contents illustrate the measurement system, measurement model and some testing results combined with specific experimental conditions, at the same time provide particular reference value on numerical control machine tool(NC machine tool) geometric precision detection.

Keywords: Laser Interferometer. Geometric Errors. Precision Detection of Machine Tool. Parameter Error Measuring.
\end{abstract}

\section{Introduction}

This paper applies the Renishaw laser interferometer to measure the geometric errors of Machining Center BV75. The geometric errors of three-axis machine tools(the twenty one items) refer to: position error of movement along the $\mathrm{X}$ axis, the $\mathrm{Y}$ axis straightness error, the $\mathrm{Z}$ axis straightness error, rolling error, pitch error, yaw error; position error of movement along the $\mathrm{Y}$ axis, the $\mathrm{Y}$ axis straightness error, the $Z$ axis straightness error, rolling error, pitch error, yaw error; position error of movement along the $\mathrm{Z}$ axis, the $\mathrm{Y}$ axis straightness error, the $\mathrm{Z}$ axis straightness error, rolling error, pitch error, yaw error; perpendicularity error between the $\mathrm{X}$ and $\mathrm{Y}$ axis, perpendicularity error between the $\mathrm{X}$ and $\mathrm{Z}$ axis, perpendicularity error between the $\mathrm{Y}$ and $\mathrm{Z}$ axis. The commonly utilized geometric error detection methods generally include single error direct measurement method and synthesis error measurement parameter identification method. This paper measures the geometric errors of machine tool with synthesis error measurement parameter identification method of nine lines.

\section{Measurement System}

\subsection{Experimental conditions of measurement system}

The research contents are the measurement of twenty one geometric errors for $\mathrm{NC}$ machine tools in this paper, therefore the first need is to determine the machine tool which can complete detection errors. Machine tools include three-axis, multi-axis, $\mathrm{NC}$ turning, $\mathrm{NC}$ milling and machining center, according to the existing machining equipment and testing equipment, select BV75 types of $\mathrm{NC}$ machining center as detection object, the geometric errors of the selected $\mathrm{NC}$ machining center are detected. The machine tool is three directions of movement, $\mathrm{X}, \mathrm{Y}, \mathrm{Z}$ axis respectively, the twenty one geometric errors detection can be completed with the detection object equipment as shown in Fig. 1.

Surrounding environment and the working state of the $\mathrm{NC}$ machine tool need to be detected before setting up the experimental system, first of all, it is need to ensure the machine tool peripheral environment without vibration source, secondly, the guide way and the main axis are feed for half an hour before measurement in order to eliminate the influence of environment temperature on the measurement results, at the same time to ensure room temperature range is relatively stable.

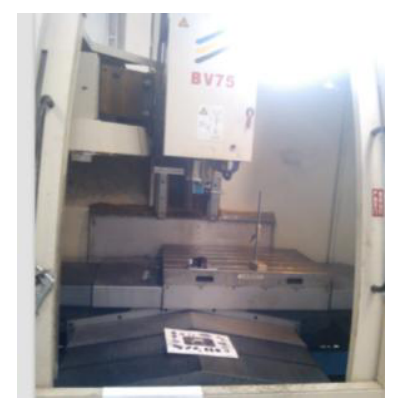

Fig. 1 BV75 numerical control machining equipment

\subsection{Components of the measurement system}

The XL-80 laser interferometer of the Renishaw company is applied for the twenty one geometric errors measurement of $\mathrm{NC}$ machine tools.

The XL-80 laser interferometer measurement system of the Renishaw company includes: XL-80 laser interferometer, tripod, data transmission line, the 
corresponding optical device (interferoscope, reflector, calibration assistant mirrors, etc.) and the corresponding application software as shown in Fig. 2.

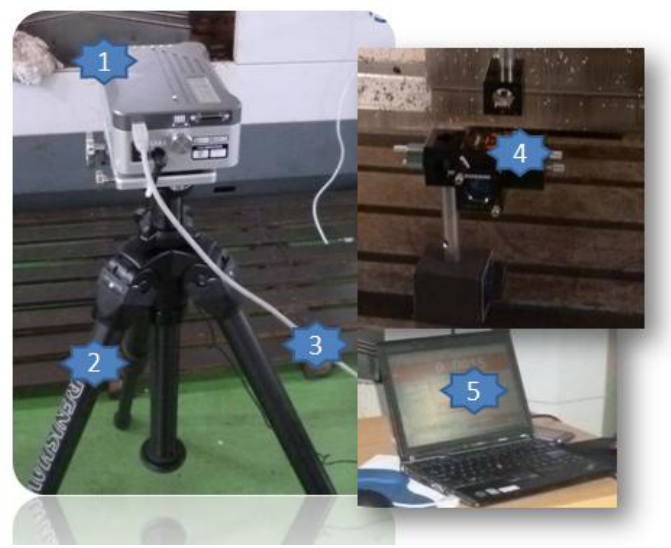

1-Laser Interferometer 2-Tripod 3-Data Transmission Line 4Optical Device 5-Test Software

Fig. 2 XL80 laser interferometer measurement system

The XL-80 optical pickup is the basis of laser interferometer, including the II helium- neon laser tube which operating wavelength is 0.633 micrometers and long-term stability is more than $1 \times 10-7$,the optical pickup also has lines associated with the laser, including not only the power of the laser tube and its stability control, but also optical detector and testing calculation circuit, which includes interference fringe counter, interpolation and signal strength function, etc. The optical pickup is connected with the test software in the computer through the data line, with which the transmission and real-time display of the testing data and the off-line data analysis are completed.

Combined with the twenty one geometric errors components of machine tools, it can be seen the position precision and linearity testing are required during the application of laser interferometer by nine line method for geometric error detection, thus the linear measurement component and the straightness measurement component need to be selected for measurement components especially optical device.

Linear measurement component includes a spectroscope, two reflectors and two targets, a spectroscope and a reflector combine together to form a mirror interference as shown in Fig. 3. The straightening alignment of the light path can also be aided with the calibration assistant mirrors in the process of calibration.

Both straightness measurement components and linear measurement components require interferoscopes and reflectors, choose different optical devices according to the measurement structure of different movement-axis which is horizontal-axis or perpendicular axis, specifically as shown in Fig. 4. The optical device is utilized to measure the straightness of the horizontal axis as shown in Fig. 4 (a), the optical device is utilized to measure the straightness of the perpendicular axis as shown in Fig. 4(b).

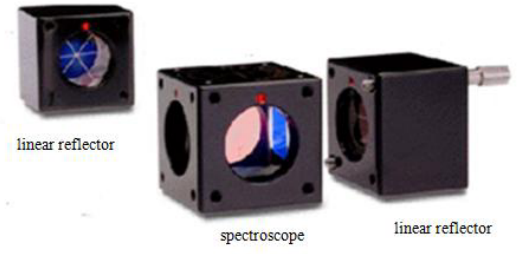

Fig. 3 Linear measurement optical device
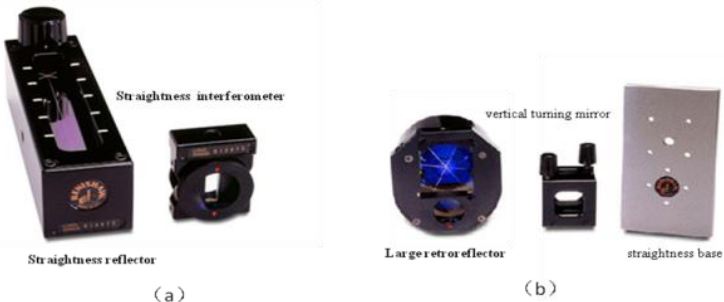

(b)

Fig. 4 Straightness measurement linear components

\section{Measurement model and content}

\subsection{Measurement Model and Content}

Detection model refers to the specific path of nine lines for specific data detection, detection content is required to determine the specific test content of each line. Specific detection of the displacement path as shown in Fig.. 5 .

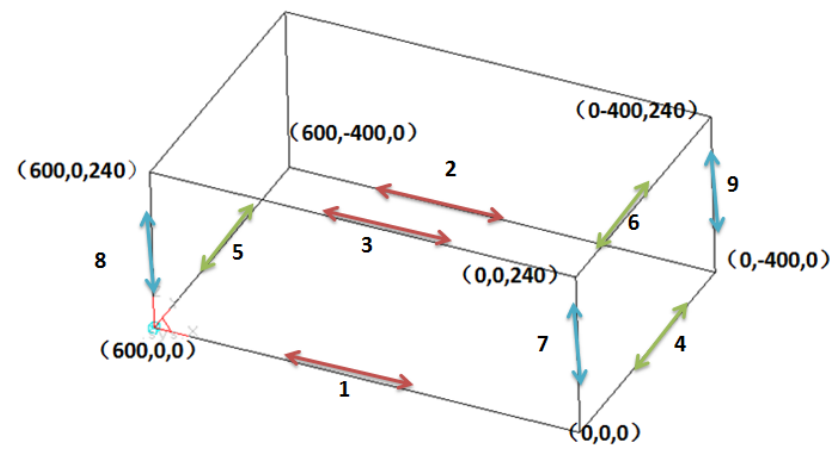

Fig. 5 Test circuit model diagram

The specific coordinates of the nine lines which is to be detected when testing is shown in Fig. 1.5, the required detected content of each line is shown in Table 1, the main test content is divided into linear displacement error and straightness error detection as shown in Table 1.

Table 1 Detection content

\begin{tabular}{|c|c|c|c|}
\hline $\begin{array}{c}\text { Line } \\
\text { number }\end{array}$ & $\begin{array}{c}\text { Starting point } \\
\text { coordinate }\end{array}$ & $\begin{array}{c}\text { End point } \\
\text { coordinate }\end{array}$ & Detection content \\
\hline 1 & $0,0,0$ & $600,0,0$ & $\begin{array}{c}\text { linear displacement } \\
\text { error; }\end{array}$ \\
\hline 2 & $0,-400,0$ & $600,-400,0$ & $\begin{array}{c}\text { linear displacement } \\
\text { error; straightness error } \\
\text { of Y axis }\end{array}$ \\
\hline 3 & $0,0,240$ & $600,0,240$ & $\begin{array}{c}\text { linear displacement } \\
\text { error; straightness errors }\end{array}$ \\
\hline
\end{tabular}




\begin{tabular}{|c|c|c|c|}
\hline 4 & $0,0,0$ & $0,-400,0$ & $\begin{array}{c}\text { of } \mathrm{Y} \text { and } \mathrm{Z} \text { axis } \\
\text { linear displacement } \\
\text { error; }\end{array}$ \\
\hline 5 & $600,0,0$ & $600,-400,0$ & $\begin{array}{c}\text { linear displacement } \\
\text { error; straightness error } \\
\text { of } \mathrm{X} \text { axis }\end{array}$ \\
\hline 6 & $0,0,240$ & $0,-400,240$ & $\begin{array}{c}\text { linear displacement } \\
\text { error; straightness errors } \\
\text { of } \mathrm{X} \text { and } \mathrm{Z} \text { axis }\end{array}$ \\
\hline 7 & $0,0,0$ & $0,0,240$ & $\begin{array}{c}\text { linear displacement } \\
\text { error; }\end{array}$ \\
\hline 9 & $600,0,0$ & $600,0,240$ & $\begin{array}{c}\text { linear displacement } \\
\text { error; straightness error } \\
\text { of } \mathrm{Y} \text { axis }\end{array}$ \\
\hline & $0,-400,0$ & $0,-400,240$ & $\begin{array}{c}\text { linear displacement } \\
\text { error; straightness errors } \\
\text { of } \mathrm{X} \text { and } \mathrm{Y} \text { axis }\end{array}$ \\
\hline
\end{tabular}

\subsection{Measurement Model and Content}

According to the Renishaw linear detection and straightness error detection process, the specific test process can be determined combined with the actual machine tool and nine-line method summarized as follows:

1. The nine-line method test model is to be established; the specific coordinate diagram of nine lines is to be established mainly combined with the actual stroke of the machine tool. When establishing model diagrams shown as Fig.1.5, first of all, the machine tools is need to be idle running, the machine tool's actual effective stroke is tested, at the same time, taking into account the space of the detection optical device for installation, the feasibility of detection, therefore to make sure the specific model of nine lines synthesized.

2, Program for the detection process.

3. Detection instrument is to be assembled and debugged, afterwards, linear and straightness error data is to be tested; in the process of testing, considering the testing efficiency and debugging repeatability, combined with the test content in Table 1 , the test sequence is determined as: test the linear error (according to 1, 2, 4, 5, $7,3,6,8,9$ line order) firstly, then straightness measurement (according to the test sequence in Table 1).

4. According to the formula of error model, the corresponding twenty one geometric errors of the machine tool can be calculated by the third step test data.

\subsection{Measurement Model and Content}

According to the linear error and the straightness error acquisition data of the nine-line method, the twenty one geometric errors of the machine tool can be obtained. Specific identification process of nine-line method by which the $\mathrm{X}$ axis six errors are obtained is as follows.

when the moving parts of machine tool move along the $\mathrm{X}$ axis, select three lines 1, 2 and 3 as shown in Fig. 6 in the workbench coordinate system, choose point A1, A2, A3 on the lines respectively, measure the displacement errors $\Delta \mathrm{X} 1(\mathrm{x}), \Delta \mathrm{X} 2(\mathrm{x})$ and $\Delta \mathrm{X} 3(\mathrm{x})$, also measure the $\mathrm{Y}$ and $\mathrm{Z}$ axis straightness errors of line $3 \Delta \mathrm{Y} 3(\mathrm{x}), \Delta \mathrm{Z} 3(\mathrm{x})$ on point $\mathrm{A} 3$, measure the $\mathrm{Y}$ axis straightness error of line $2 \Delta \mathrm{Y} 2(\mathrm{x})$ on point $\mathrm{A} 2$, according to the geometric characteristics of the intrinsic error, displacement errors are produced such as $\delta \mathrm{z}(\mathrm{x})$ on $\mathrm{X}$ and $\mathrm{Y}$ direction, $\delta \mathrm{y}(\mathrm{x})$ on $\mathrm{X}$ and $\mathrm{Z}$ direction, $\delta \mathrm{x}(\mathrm{x})$ on $\mathrm{Y}$ and $\mathrm{Z}$ direction as well, six relations are obtained as follows from Fig.6.

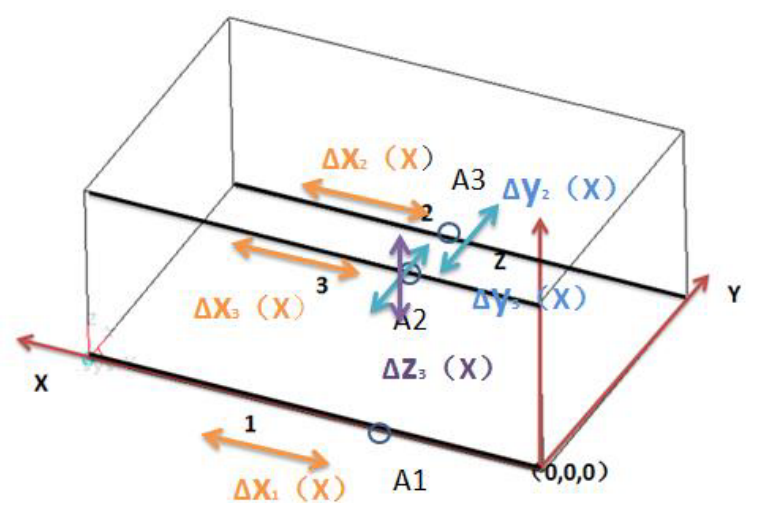

Fig. 6 parameter identification of the movement along the $\mathrm{X}$ axis

By detecting the corresponding displacement errors and straightness errors on line 1, 2, and 3, six geometric errors of the $\mathrm{X}$ axis direction can be calculated from Equation 1: the position error of the movement along the $\mathrm{X}$ axis, the $\mathrm{Y}$ axis straightness error, the $\mathrm{Z}$ axis straightness error, rolling error, pitch error and yaw error. The specific measurement results are shown in Fig. 7.

$$
\left.\begin{array}{c}
\Delta X_{1}(\mathrm{x})=\Delta X(x) \\
\Delta \mathrm{X}_{2}(\mathrm{x})=\Delta \mathrm{X}(x)-\delta_{\mathrm{z}}(x) y_{2} \\
\Delta Y_{2}(x)=\Delta Y(x)+\delta_{z}(x) x_{2} \\
\Delta X_{3}(x)=\Delta X(x)+\delta_{y}(x) \mathrm{z}_{3} \\
\Delta Y_{3}(x)=\Delta Y(x)-\delta_{x}(x) z_{3}+\delta_{z}(x) x_{3} \\
\Delta Z_{3}(x)=\Delta Z(x)-\delta_{y}(x) \mathrm{x}_{3}
\end{array}\right\}
$$

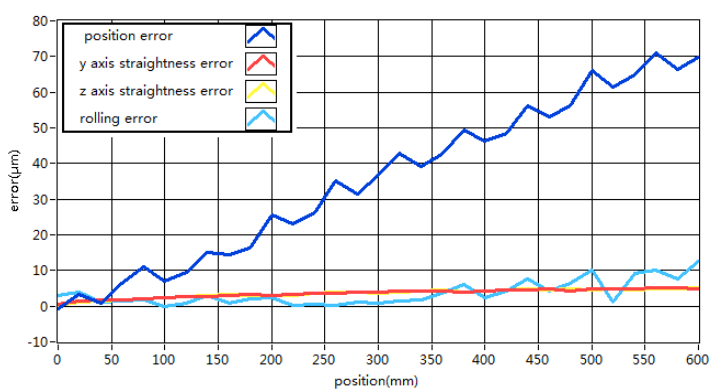

Fig.7 Measurement results for geometric errors of the movement along the $\mathrm{X}$ axis

\section{Conclusion}

This paper determines the error detection model with the laser interferometer, twenty one geometric errors of $\mathrm{NC}$ machine tools can be calculated through the specific 
detection methods, it has certain advantages compared with geometric errors detected separately item by item in the $\mathrm{X}$ line.

\section{Acknowledgment}

This research was supported by Beijing Young Talent Project of Ministry of Educ-ation (PXM2014-014225000010), Beijing areal Project of Ministry of Education (PXM2014-014225-000007), Beijing Industry Vocational and Technical College Project of key research topic (PXM110551505/002).

\section{References}

1. Zhu Chizhou. Research on Modeling and Compensation Technique for 3-Dimension Volumetric Errors of CNC Machine Tools[A]. Thesis for the Degree of Master of Engineering. 2012: 22-23.

2. Su Shiping. Study on the Methods of Precision Modeling and Error Compensation for Multi-Axis CNC Machine Tools[A]. Dissertation for the Degree of Philosophy Doctor in Engineering. 2002: 86-88.

3. Chen Jinying. Based on the detection and analysis of Thermal Error of CNC Milling BV75. Modular machine tools \& automatic manufacturing technique, 2015(4): 101-103.

4. Liu Huanlao. Research on the Geometric Error Measurement and Error Compensation of the Numerical Control Machine Tools[A]. Huazhong University of Science and Technology. 2002: 86-88.

5. M.Anjanappa, D.K.Anand, J.A.Kirk. Error correetion methodologies and control strategies for mumerical control maehines[J]. Control Method for Manufaeturing Proeess. 1998(7): 41-49.

6. K.Kim, M.K.Kim. Volumetric accuracy analysis based generalied geometric error model in multi-axes maehine tools, Mech. Macb. Theory. 1991(26): 207219.

7. Chen Guiquan, Yuan Jingxia. A Displacement Measurement Approach for Machine Geometric Error Assessment[J]. International Journal of Maehine Tools \& Manufaeture. 2001, 41(1): 149-161

8. Li Huanling, $\mathrm{Wu}$ hongtao.Three coordinate nc machine tool geometric error parameters identification.,Machinery manufacturing. 2008(46): $5-7$. 